\title{
CARCINOMA ESPINOCELULAR DO CONDUTO AUDITIVO EXTERNO: ESTUDO POR TOMOGRAFIA COMPUTADORIZADA DE SEIS CASOS*
}

\author{
Fábio Mota Gonzalez ${ }^{1}$, Ademar José de Oliveira Paes Junior ${ }^{1}$, Olger de Souza Tornin², \\ Ricardo Pires de Souza ${ }^{3}$
}

Resumo OBJETIVO: Analisar a importância da avaliação tomográfica da extensão profunda dos carcinomas espinocelulares do conduto auditivo externo. MATERIAIS E MÉTODOS: Foram realizados exames tomográficos com cortes axiais e coronais com janelas para partes moles e óssea em seis pacientes com carcinoma espinocelular do conduto auditivo externo, com idade variando entre 55 e 71 anos, internados no Hospital Heliópolis, no período entre maio de 1995 e dezembro de 2003. RESULTADOS: Dos seis pacientes, todos apresentavam aumento de partes moles no conduto auditivo externo, cinco $(83,3 \%)$ tinham erosão óssea e invasão da orelha média, quatro $(66,7 \%)$ possuíam comprometimento da mastóide e da glândula parótida, três $(50 \%)$ apresentavam invasão da articulação temporomandibular, dois $(33,3 \%)$ tinham invasão da fossa média, do canal carotídeo e linfonodomegalia júgulo-carotídea alta ipisilateral. CONCLUSÃO: A avaliação da extensão tumoral profunda fornecida pela tomografia computadorizada é importante no estadiamento clínico, possibilitando um planejamento terapêutico mais eficaz.

Unitermos: Carcinoma espinocelular; Conduto auditivo externo; Tomografia computadorizada.

Abstract Squamous cell carcinoma of the external auditory canal: computed tomography findings in six cases.

OBJECTIVE: To evaluate the role of computed tomography in the assessment of deep extension of squamous cell carcinoma of the external auditory canal. MATERIALS AND METHODS: In the period between May 1995 and December 2003 six patients with squamous cell carcinoma of the external auditory canal were submitted to computed tomography scan at "Hospital Heliópolis", São Paulo, SP, Brazil, including axial and coronal slices with soft tissue and bone algorithms. RESULTS: Thickening of the soft tissue of the external auditory canal was seen in all patients, bone erosion and invasion of the middle ear in five $(83.3 \%)$, invasion of the mastoid and parotid gland in four $(66.7 \%)$, invasion of the temporomandibular joint in three $(50 \%)$, and invasion of the middle cranial fossa, carotid canal and cervical lymph node enlargement in two (33.3\%) patients. CONCLUSION: Assessment of deep extension of squamous cell carcinoma of the external auditory canal using computed tomography is useful for clinical staging of the disease allowing better therapeutic planning for these patients.

Key words: Squamous cell carcinoma; External auditory canal; Computed tomography.

\section{INTRODUÇÃO}

Os cânceres do conduto auditivo externo (CAE) são raros, com uma incidência de $1 / 1.000 .000$ de habitantes/ano ${ }^{(\mathbf{1})}$, e representam menos que $0,2 \%$ dos tumores da

\footnotetext{
* Trabalho realizado no Serviço de Diagnóstico por Imagem do Complexo Hospitalar Heliópolis, São Paulo, SP.

1. Médicos Residentes do Serviço de Diagnóstico por Imagem do Complexo Hospitalar Heliópolis, Mestrandos do Curso de Pós-graduação em Ciências da Saúde do Hospital Heliópolis (Hosphel).

2. Médico Residente do Serviço de Diagnóstico por Imagem do Complexo Hospitalar Heliópolis.

3. Coordenador do Programa de Residência Médica em Radiologia e Diagnóstico por Imagem do Complexo Hospitalar Heliópolis.

Endereço para correspondência: Dr. Fábio Mota Gonzalez. Rua Sena Madureira, 826, ap. 21, Vila Clementino. São Paulo, SP, 04021-001. E-mail: fmg961@yahoo.com.br

Recebido para publicação em 30/7/2004. Aceito, após revisão, em 9/12/2004.
}

cabeça e pescoço ${ }^{(2)}$. Um grupo variado de neoplasias malignas pode acometer essa região. O carcinoma espinocelular (CEC) e o basocelular são os mais comuns, sendo o CEC muito mais freqüente ${ }^{(3-5)}$.

O CEC do CAE acomete indivíduos entre a quinta e a sétima década de vida, sendo mais freqüente em mulheres ${ }^{(4)}$. Os sintomas de apresentação são variados, incluindo otalgia, sangramentos, otorréia, tontura surdez e paralisia do facial ${ }^{(6)}$. A apresentação clássica é otalgia e otorréia num paciente com história de otite crônica, que é relatada em pelo menos um terço dos pacientes ${ }^{(\mathbf{4 , 5})}$.

Os CEC do CAE se disseminam primariamente por extensão direta. Linfonodomegalia não é comum, e quando ocorre acomete as cadeias retrofaringeas, pré-au- riculares e cervicais mais superiores. Metástases a distância são raras. Os principais sítios acometidos pela disseminação tumoral são a orelha média, a glândula parótida, o pavilhão auricular, a articulação temporomandibular (ATM), o nervo facial, e através da disseminação inferior pode envolver ainda o canal carotídeo e a fossa jugular. A partir da orelha média o tumor pode acometer superiormente o tegmen timpânico e posteriormente as células da mastóide e, eventualmente, a partir desses sítios, invadir as fossas cranianas média e posterior, respectivamente ${ }^{(\mathbf{4 , 7})}$.

Os fatores de mau prognóstico são tumor extenso, paralisia do nervo facial, linfonodomegalia cervical ou parotídea ${ }^{(3)}$. A invasão da orelha média é outro fator de mau prognóstico, que quando ocorre leva 
a uma redução da sobrevida em cinco anos de $59 \%$ para $23 \%{ }^{(8)}$.

O diagnóstico definitivo desses tumores é realizado por meio de biópsia da lesão. O estadiamento pré-operatório é realizado através do exame clínico e dos exames de imagem, sendo a tomografia computadorizada (TC) e a ressonância magnética (RM) os principais métodos utilizados. A avaliação precisa da extensão local e da linfonodomegalia associada é fundamental para otimizar o planejamento terapêutico, uma vez que a ressecção incompleta reduz drasticamente a chance de cura ${ }^{(9)}$.

O tratamento dessas lesões é a ressecção completa associada a radioterapia adjuvante nos casos mais avançados. A radioterapia isolada é reservada para os tumores irressecáveis ${ }^{(2,3,9)}$.

O objetivo deste trabalho é analisar a importância da TC na avaliação da extensão profunda tumoral dos CEC do CAE.

\section{MATERIAIS E MÉTODOS}

Foram analisados, retrospectivamente, por um radiologista com experiência na região de interesse, seis pacientes com CEC do CAE. Todos os casos eram virgens de tratamento e tiveram seu diagnóstico confirmado por estudo anatomopatológico.

A faixa etária dos pacientes variou de 55 a 71 anos, com idade média de 60 anos. Dois eram mulheres e quatro eram homens (Tabela 1).

Os exames de TC foram realizados em aparelho de terceira geração, obtendo-se imagens seccionais com espessura de corte e incremento de $2 \mathrm{~mm}$ nos planos axiais e coronais com janelas para osso e partes moles. Seqüências adicionais com espessura e incremento de $5 \mathrm{~mm}$ foram utilizadas na avaliação do pescoço. Foi administrado meio de contraste endovenoso iodado utilizando $100 \mathrm{ml}(300 \mathrm{mg} / \mathrm{ml})$ por paciente.

Em cada exame foram avaliados o acometimento de partes moles, a erosão óssea do CEA, a orelha média, a mastóide, a ATM, as fossas cranianas média e posterior, o canal carotídeo e a fossa jugular, além da invasão da glândula parótida e da presença de linfonodomegalia.

Os dados clínicos foram obtidos através de revisão dos prontuários, possível em cinco dos seis pacientes.

Tabela 1 Dados clínicos, estadiamento TNM, terapêutica empregada e correlação cirúrgico-radiológica.

\begin{tabular}{|l|l|c|c|c|c|l|}
\hline Pacientes & Sexo & $\begin{array}{c}\text { Paralisia } \\
\text { do facial }\end{array}$ & Terapêutica & $\begin{array}{c}\text { Estágio } \\
\text { tumoral }\end{array}$ & Idade & $\begin{array}{c}\text { Correlação } \\
\text { cirúrgico- } \\
\text { radiológica }\end{array}$ \\
\hline M.J. & Feminino & Não & Cirurgia + radioterapia & T3NOMO & 57 anos & Positiva \\
B.R. & Masculino & Sim & Cirurgia + radioterapia & T4NOMO & 63 anos & Negativa \\
A.F.B. & Masculino & Sim & Cirurgia + radioterapia & T4N1MO & 59 anos & Positiva \\
A.C. & Feminino & Não & Cirurgia & T1NOMO & 71 anos & Positiva \\
P.A. & Masculino & Sim & Radioterapia & T4N1MO & 55 anos & Não realizada \\
A.P. & Masculino & Sim & Cirurgia + radioterapia & T4NOMO & 55 anos & Positiva \\
\hline
\end{tabular}

Quadro 1 Sistema para estadiamento de carcinoma espinocelular do osso temporal da Universidade de Petersburgo.

\begin{tabular}{|c|c|}
\hline Estágio & Descrição \\
\hline \multicolumn{2}{|l|}{ Estágio T } \\
\hline $\mathrm{T} 1$ & $\begin{array}{l}\text { Tumor limitado ao conduto auditivo externo, sem evidência de erosão óssea ou de exten- } \\
\text { são para partes moles. }\end{array}$ \\
\hline $\mathrm{T} 2$ & $\begin{array}{l}\text { Tumor com erosão parcial do conduto auditivo externo ou achado radiológico compatível } \\
\text { com extensão limitada para partes moles }(<0,5 \mathrm{~cm}) \text {. }\end{array}$ \\
\hline T3 & $\begin{array}{l}\text { Tumor erodindo toda a espessura do conduto auditivo externo, com limitada extensão para } \\
\text { partes moles }(<0,5 \mathrm{~cm}) \text {, ou tumor invadindo a orelha média e/ou mastóide. }\end{array}$ \\
\hline T4 & $\begin{array}{l}\text { Tumor erodindo a cóclea, o ápex do osso petroso, parede medial da orelha média, canal } \\
\text { carotídeo, forame jugular ou com extenso envolvimento de partes moles }(>0,5 \mathrm{~cm}) \text { e } \\
\text { pacientes apresentando paralisia do nervo facial. }\end{array}$ \\
\hline Estágio N & $\begin{array}{l}\text { Linfonodomegalia é indicativo de prognóstico ruim, colocando os pacientes em um está- } \\
\text { gio mais avançado (por exemplo: T1N1M0 [estágio III] e T2, T3 e T4, N1 [estágio IV]). }\end{array}$ \\
\hline Estágio M & M1 é estágio IV e é considerado como tendo prognóstico muito ruim. \\
\hline
\end{tabular}

O estadiamento pré-operatório foi realizado com base no sistema de estadiamento da Universidade de Petersburgo para CEC do osso temporal (Quadro 1).

\section{RESULTADOS}

Dentre os seis pacientes, $100 \%$ apresentavam aumento de partes moles no CAE. Erosão óssea da orelha média foi encontrada em cinco pacientes $(83,3 \%)$. O acometimento da glândula parótida e da mastóide foi observado em quatro casos $(66,7 \%)$. A ATM estava comprometida em três casos $(50 \%)$. O canal carotídeo e a fossa média apresentavam sinais de invasão em dois pacientes $(33,3 \%)$, sendo que um deles também tinha invasão da fossa posterior. Linfonodomegalia júgulo-carotídea alta ipisilateral foi encontrada em dois casos $(33,3 \%)$ (Tabela 2$)$.

Nos cinco pacientes em que foi possível a revisão do prontuário, a queixa de otite de repetição estava presente em três (50\%). Dor local e secreção abundante também foram referidas por esses três.
Quatro dos pacientes $(66,7 \%)$ procuram atendimento com quadro clínico de paralisia facial já instalado.

A correlação dos achados tomográficos com os achados intra-operatórios foi possível em cinco casos, havendo dúvida com relação à avaliação tomográfica da extensão tumoral em um dos casos em que na TC não era possível identificar com segurança se havia invasão da dura-máter com comprometimento encefálico do lobo temporal, fato que foi confirmado na cirurgia. Com relação à linfonodomegalia, o exame anatomopatológico confirmou envolvimento tumoral em um dos casos e hiperplasia reacional no outro.

A grande maioria dos pacientes apresentava estadiamento avançado no momento da avaliação inicial, sendo quatro deles T4 (dois T4N0M0 e dois T4N1M0), um T3N0M0 e um T1N0M0 (Tabela 1).

\section{DISCUSSÃO}

Embora rara, essa doença merece destaque pela história bastante sugestiva de 
Tabela 2 Avaliação da extensão tumoral pela tomografia.

\begin{tabular}{|c|c|c|c|c|c|c|c|c|c|c|}
\hline Pacientes & $\begin{array}{c}\text { Extensão } \\
\text { para partes } \\
\text { moles }\end{array}$ & $\begin{array}{c}\text { Erosão óssea } \\
\text { do conduto } \\
\text { auditivo } \\
\text { externo }\end{array}$ & $\begin{array}{l}\text { Invasão } \\
\text { da orelha } \\
\text { média }\end{array}$ & $\begin{array}{c}\text { Invasão } \\
\text { da mastóide }\end{array}$ & $\begin{array}{c}\text { Invasão } \\
\text { da articulação } \\
\text { temporo- } \\
\text { mandibular }\end{array}$ & $\begin{array}{l}\text { Invasão } \\
\text { da fossa } \\
\text { média }\end{array}$ & $\begin{array}{l}\text { Invasão } \\
\text { da fossa } \\
\text { posterior }\end{array}$ & Linfonodos & $\begin{array}{l}\text { Glândula } \\
\text { parótida }\end{array}$ & $\begin{array}{c}\text { Canal } \\
\text { carotídeo }\end{array}$ \\
\hline M.J. & Sim & Sim & Sim & Sim & Não & Não & Não & Não & Não & Não \\
\hline B.R. & Sim & Sim & Sim & Sim & Não & Não & Não & Não & Sim & Não \\
\hline A.F.B. & Sim & Sim & Sim & Sim & Sim & Sim & Sim & Sim & Sim & Sim \\
\hline A.C. & Não & Não & Não & Não & Não & Não & Não & Não & Não & Não \\
\hline P.A. & Sim & Sim & Sim & Sim & Sim & Sim & Não & Sim & Sim & Sim \\
\hline A.P. & Sim & Sim & Sim & Não & Não & Não & Não & Não & Sim & Não \\
\hline
\end{tabular}

Figura 1. Paciente M.J., sexo feminino, 57 anos de idade. A: Corte axial janela óssea carcinoma espinocelular do conduto auditivo externo direito com extensão para oreIna média, erosão da parede da mastóide e obliteração das células da mastóide. $\mathbf{B}$ : Corte coronal janela óssea obliteração do conduto auditivo externo associada a destruição da parede óssea inferior do conduto.

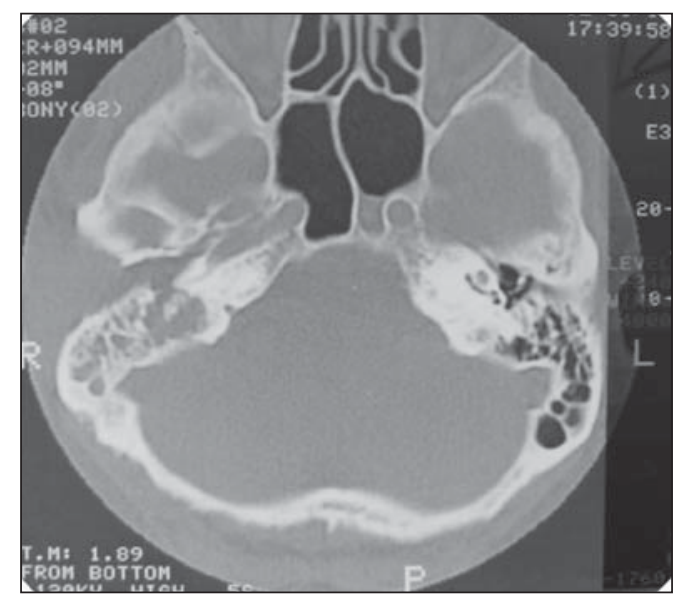

A

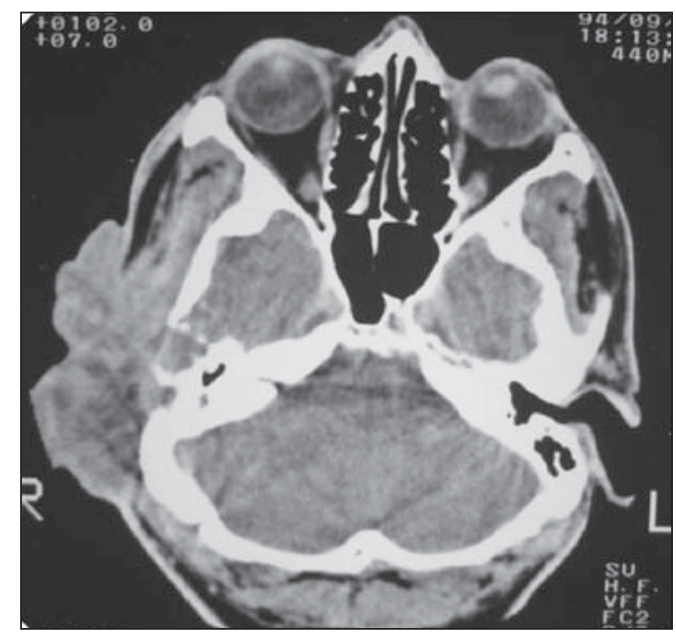

A

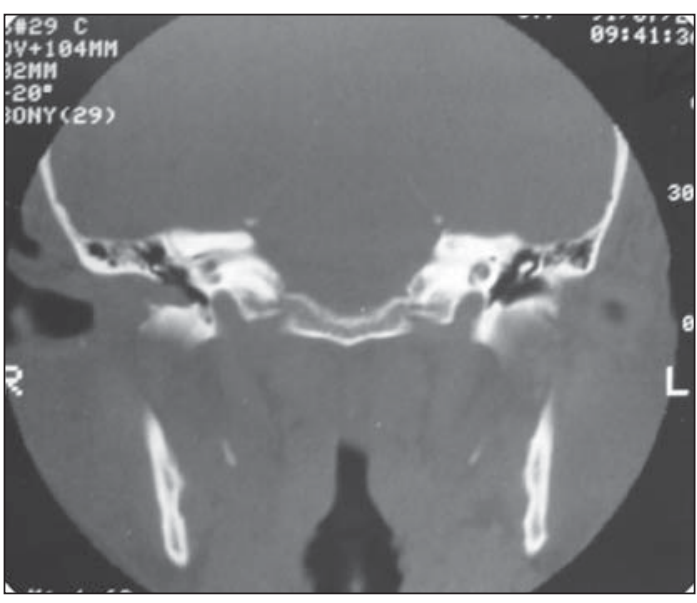

B

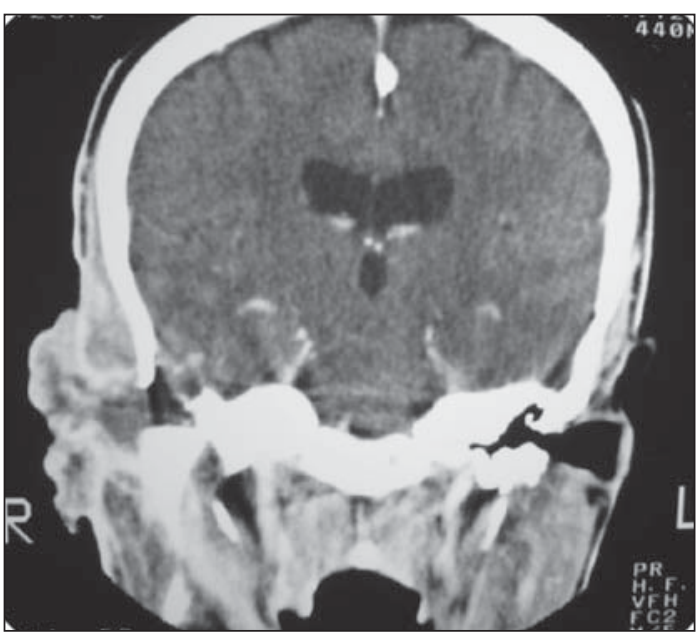

B

Figura 2. Paciente A.B., sexo masculino, 59 anos de idade. A: Corte axial - carcinoma espinocelular do conduto auditivo externo direito com grande componente de partes moles, com comprometimento do pavilhão auricular e invasão da fossa craniana média. B: Corte coronal - massa com densidade de partes moles obliterando o conduto auditivo externo e condicionando erosão de suas paredes ósseas e da base do crânio.

otites de repetição, dor e secreção de longa data ${ }^{(3,4,7)}$, conforme observado na presente casuística.

O principal papel do radiologista no CEC do CAE é o estadiamento e não o diagnóstico, que é clínico e anatomopatológico. A exemplo de inúmeras outras enfermidades, especialmente as neoplásicas, os achados da avaliação radiológica não são específicos.

O estadiamento radiológico é realizado por meio de exames seccionais (TC e RM), visando principalmente à analise da extensão profunda da lesão, já que a disseminação linfonodal e as metátases não são eventos freqüentes ${ }^{(\mathbf{4 , 5}, \mathbf{8})}$.
O exame tomográfico deve ser realizado nos planos axiais e coronais com janela óssea e partes moles. Os cortes axiais permitem uma boa avaliação do CAE, cápsula ótica, forame jugular, canal do nervo facial e do tegmen timpânico, e os coronais, uma melhor caracterização do soalho e do teto da orelha média, do tegmen timpânico, das 


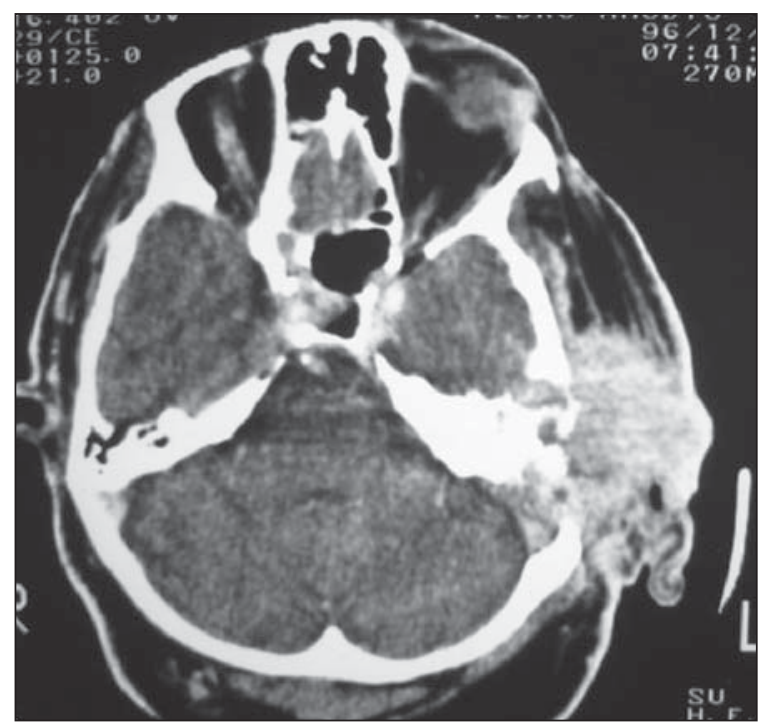

A
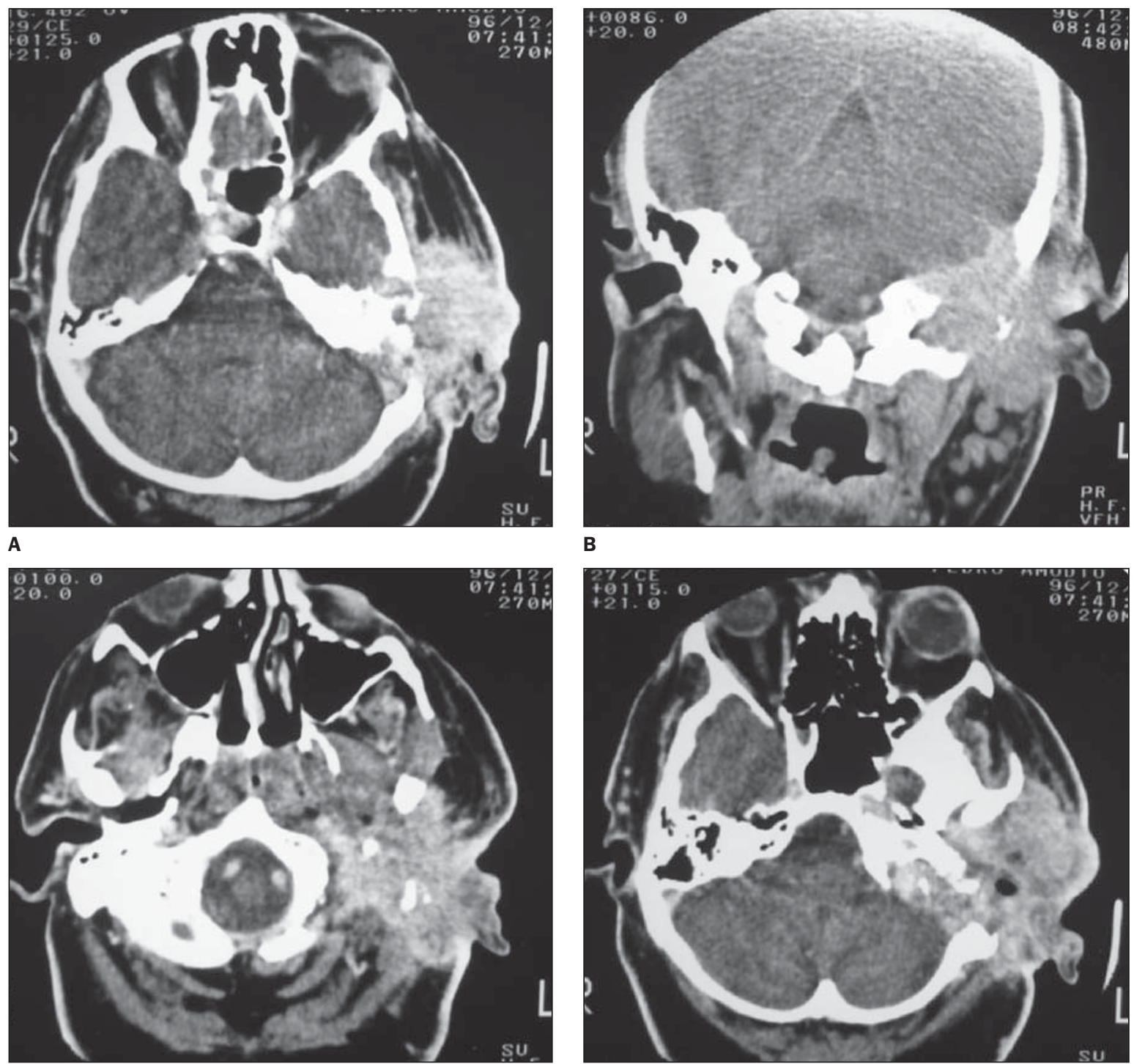

B

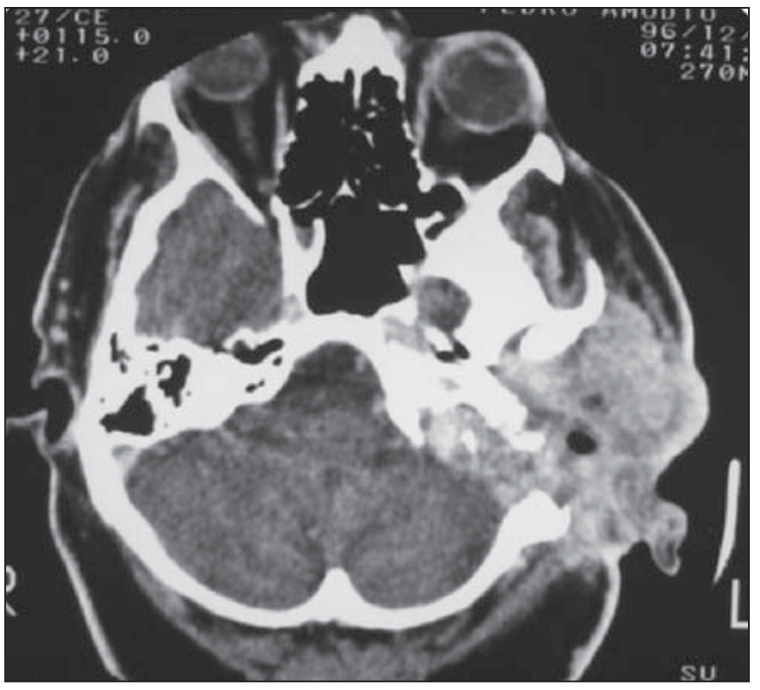

D

Figura 3. Paciente P.A., sexo masculino, 55 anos de idade. A: Corte axial - carcinoma espinocelular do conduto auditivo externo esquerdo com grande componente de partes moles e extensão para fossa craniana média e posterior. B: Corte coronal - massa com densidade de partes moles obliterando o conduto auditivo externo, erodindo a base do crânio e invadindo a fossa posterior. C: Corte axial - comprometimento da articulação temporomandibular com deslocamento anterior do côndilo da mandíbula e extensão retroestiliana do tumor. D: Corte axial - destruição da mastóide esquerda e extensão para fossa posterior.

paredes superior e inferior do CAE, do teto da fossa jugular e do canal carotídeo. O contraste endovenoso é essencial para melhor definição da extensão do tumor para a glândula parótida, fossa infratemporal e para a dura-máter ${ }^{(4)}$. A TC nos fornece avaliação precisa do comprometimento ósseo local, sendo o melhor método para identificar estágios iniciais de erosão óssea ${ }^{(\mathbf{4 , 8 , 9 )}}$. A RM vem sendo utilizada conjuntamente com a TC em alguns centros. As principais vantagens apontadas são a melhor definição das margens tumorais com os tecidos moles adjacentes, melhor caracterização da invasão intracraniana, do seio sigmóide e da porção cavernosa da artéria carótida, além da melhor caracterização do envolvimento do nervo facial ${ }^{(2,}$ ${ }^{4,9)}$. Na série estudada, a TC permitiu boa avaliação da extensão tumoral e da disseminação linfática, em concordância com a literatura $^{(\mathbf{2 , 8 , 9 )}}$, sendo, ao nosso ver, suficiente para um correto estadiamento. Nas instituições onde se dispuser de fácil acesso para a realização da RM, esta poderia ser realizada em conjunto com a TC nos casos mais avançados quando houvesse dúvida com relação à extensão tumoral.
O estadiamento de tais lesões é importante para o planejamento terapêutico, baseado na cirurgia e radioterapia adjuvante ou radioterapia exclusiva (casos avançados, com comprometimento da fossa craniana média, posterior ou canal carotídeo, por exemplo). Casos localmente avançados são freqüentes, fato provavelmente relacionado ao não reconhecimento da natureza neoplásicas da lesão, algo que é dramático, especialmente em populações carentes, característica da série estudada, pois o retorno ao profissional médico é bastante difícil. 
O diagnóstico diferencial de tais lesões deve incluir lesões de origem congênita, inflamatória e tumoral de outra natureza.

Entre as causas destacadas, a atresia do CAE é a causa congênita mais frequiente. Como causas inflamatórias, além da otite externa comum, destacamos a otite externa maligna, o colesteatoma e a ceratose obturante (bilateral associada à sinusite crônica, bronquiectasias na faixa etária acima dos 40 anos). Os tumores benignos podem surpreender o médico, como o ceruminoma, que além de formar uma massa de partes moles pode provocar erosão óssea, sugerindo agressividade, mais freqüente em doenças malignas. Especial atenção deve ser dada aos tumores malignos que podem mimetizar as lesões estudadas. Devem-se destacar o carcinoma basocelular, o melanoma, o adenocarcinoma e o carcinoma adenóide cístico. As neoplasias malignas que comumente geram metástases para o CAE por via hematogênica originam-se na mama, próstata, pulmão, rim e tireóide. Os cânceres da pele, parótida, nasofaringe, cérebro e meninges acometem o CAE por disseminação direta. Doenças linfoproliferativas como leucemia, linfoma e mieloma também podem disseminar-se por via hematogênica para o CAE. A histiocitose $\mathrm{X}$ também pode acometer o CAE em até $15 \%$ dos pacientes ${ }^{(3,5)}$.

\section{CONCLUSÃO}

A avaliação da extensão profunda e da disseminação linfática fornecida pela TC é importante no estadiamento dos CEC do CAE, possibilitando um planejamento terapêutico mais eficaz, fator esse indispensável na tentativa de melhorar o prognóstico sombrio dessa doença.

\section{REFERÊNCIAS}

1. Nyrop M, Grontved A. Cancer of the external auditory canal. Arch Otolaringol Head Neck Surg $2002 ; 128: 834-7$.
2. Moody SA, Hirsch BE, Myers EN. Squamous cell carcinoma of the external auditory canal: an evaluation of a staging system. Am J Otol 2000;21:5828.

3. Som PM, Curtin HD. Temporal bone tumors and cerebellopontine angle lesions. In: Som PM, Curtin HD, eds. Head and neck imaging. 4th ed. St. Louis: Mosby, 2003:1340-2.

4. Friedman DP, Rao VM. MR and CT of squamous cell carcinoma of the middle ear and mastoid complex. AJNR 1991;12:872-4.

5. Phelps PD, Lloyd GA. The radiology of carcinoma of the ear. Br J Radiol 1981;54:103-9.

6. Haaga JR, Lanzieri CF, Sartorie BJ, Zerhouni EO. Tomografia computadorizada e ressonância magnética do corpo humano. 3 a ed. St. Louis: Mosby, 1994:384-421.

7. Clark LJ, Narula AA, Morgan DAL, Bradley PJ. Squamous carcinoma of the temporal bone: a revised staging. J Laryngol Otol 1991;105:346-8.

8. Bird CR, Hasso AN, Stewart CE, Hinshaw DB Jr, Thompson JR. Malignant primary neoplasms of the ear and temporal bone studied by high-resolution computed tomography. Radiology 1983; 149:171-4.

9. Horowitz SW, Leonetti JP, Azar-Kia B, Fine M, Izquierdo R. CT and MR of temporal bone malignancies primary and secondary to parotid carcinoma. AJNR 1994;15:755-62. 